\title{
READERS
Insight
}

Journal of Management Info (JMI)

ISSN:2313-3376

www.readersinsight.net/jmi

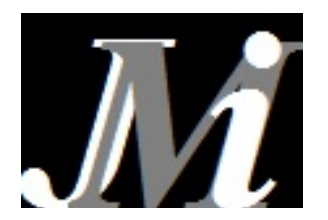

\section{Potential causes and outcomes of communication conflicts at the workplace -A qualitative study in Pakistan}

\author{
Sadia Deep*1, Berhanuddin Mohd Salleh ${ }^{1}$, Hussain Othman ${ }^{1}$ \\ ${ }^{1}$ Faculty of Science Technology \& Human Development, Universiti Tun Hussein Onn Malaysia
}

* Corresponding author: sadiadeep@gmail.com

\begin{abstract}
Occurrence of communication conflict among employees is a natural phenomenon at any workplace and for effective resolution of these conflicts, it is indispensable to know the potential factors triggering these conflicts and making them destructive. This paper intends to investigate the causes, outcomes and the subsequent resolutions of communication conflicts among employees at workplace in the development sector in Pakistan. The data for this qualitative study was gathered from library research and semi-structured interviews taken from eighteen employees belonging to the three development organizations from areas of Peshawar and Islamabad in Pakistan. To derive sample for this study, a purposeful sampling technique was used. The analysis and transcription of the interviews were made following thematic techniques. The findings from this study reveal that poor communication, misunderstanding and lack of other soft skills and traits as the significant causes of the communication conflicts while lack of trust, stress, resignation and transfers are found to be potential outcomes. Some suggestions such as strong leadership and training of employees are also given for the effective resolution of these conflicts.
\end{abstract}

Keywords: Communication Conflict, Workplace, Conflict Resolution

\section{ARTICLE INFORMATION}

Received: 25 March 2016

Revised: 25 June 2016

Accepted: 25 August 2016

DOI:

http://dx.doi.org//10.31580/jmi.v11i1.54

\section{Introduction}

Being natural and inevitable in itself, conflicts occur where there are human beings but knowing the core causes and dealing with employee conflict in a timely manner is, however, important to maintain a healthy work environment (Farooqi, 2013; Yildiz \& Bumen, 2013). Simple conflicts can grow into severe problems if not dealt with appropriately. Believing that a conflict will simply disappear or turn into a fruitful outcome, without any effort of resolving it, are inaccurate assumptions to make (De Dreu, 2008). Employees should try to understand the common causes of employee conflicts so that a solution is found before the issues become unmanageable and entails into an irreparable loss.

There has also been a significant rise in the communication conflicts among employees at the workplaces in Pakistan (Mansoor, Fida, Nasir, \& Ahmad, 2011; Nasir \& Bashir, 2012; Noor \& Maad, 2009). The irony of the fact is that these conflicts are widely hidden and avoided instead of resolving them effectively (Chaudhry, 2011; Farooqi, 2013). These communication conflicts are at times so severe that it leads to verbal abuse at workplace destroying the professional environment within the organizations (Cassum, 2014).

The available literature pinpoints some common causes of these conflicts at the workplace. Among them, poor communication is one of the leading causes of conflict between employees in the workplace. Failing to communicate in the workplace may cause employees to make incorrect assumptions. Poor communication in the workplace not only causes conflict but decreases productivity and employee morale (Manning, 2014; Pandey, Pandey, \& Kothari, 2016).
The difference in personalities also causes a conflict at workplace conflict. Employees have diverse personalities due to their different backgrounds and experiences. Problems tend to arise in the workplace when employees fail to accept the differences in each other's personalities. When employees fail to accept the differences, coworkers may insult each other's character and experiences (Ameen, 2013; Ferreira, 2012; Mirza, 2014). Unhealthy workplace competition also serves as a cause of conflict among employee at the workplace. Some workplaces foster competitive environments more than others. When salary is linked to employee's productivity, a workplace may experience strong competition among employees. Competition not properly managed can result in employees sabotaging or insulting one another resulting in the creation of a hostile work environment. Unhealthy workplace competition at most of the time, therefore, discourages teamwork and promotes individualism (Nickson, Warhurst, Commander, Hurrell, \& Cullen, 2012; Sultana, 2015). In literature, the cost of conflict is divided into hard and soft costs. Hard costs are measurable costs. They are tangible and usually easy to find and add up such as wasted time, lost workdays, reduced productivity, performance and quality, Healthcare costs associated with stress, sabotage and theft turnover, termination packages, legal costs (Ayoko, 2003; Brockman, 2013).

On the other hand, Soft costs are those things that may not seem measurable but they still affect your bottom line like morale, decreased customer service, reputation, loss of skilled employees (Vivian S, 2016).

This part of study focus this subject for research as there is not a considerable amount of empirical research to investigate into the 
causes and outcomes of triggering communication conflicts in the developing sector, especially in the Pakistani context. The field of study is especially ignored in the context of the professional environment in Pakistan. This exploratory study being a part of a larger study, therefore, focuses on ascertaining the contributive causes and effects of communication conflicts in three developing organizations in the Pakistan. The following question guided the study i.e. what are the potential causes of communication conflicts among employees at the workplace and their impact on the workplace? What are the effective measures or strategies to resolve communication conflict at the workplace?

\section{Study design and method}

Three developing organizations namely Community Motivation Development Organization (CMDO) Peshawar, Read Foundation and International Catholic Migration Commission (ICMC) Islamabad, Pakistan served the population for this study. The selection of these organizations was based on the willingness on the part of the head of these organizations. The researcher had contacted many organizations but three out of around six accepted the support and allowed their staff for the training and subsequent interviews. As the part of a larger doctoral study, this research effort selected eighteen respondents for the semi-structured interview out of the forty employees who got three days training based on PBL approach. The eighteen respondents out of total forty for the qualitative study were chosen on the basis of their willingness. The sample had been filtered through criteria on the basis of their length of working experience and number of organizations served by a purposeful sampling approach This study used a semi-structured interview method to collect the data qualitatively (see Appendix 1 for the interview questions). In a semistructured interview, the researcher asks a series of open-ended questions with accompanying queries that probe for more detailed and contextual data (Piercy, 2015). A semi-structured interview is a verbal interchange when one person, the interviewer, tries to elicit information from another person by asking questions. Although the researcher prepares a list of predetermined questions, but it provides the interviewer with a chance to explore what they feel are important (Longhurst, 2003). The researcher opted for the semi-structured interview as the data collecting tool due to its suitability to the subject and its benefits over other tools such as it allows the researcher to be prepared well in advanced and appear competent during the interview ; besides, it also allow the respondents to express their views in their own terms (Cohen \& Crabtree, 2006) as was required for this study. We used the qualitative method in order to explore the subject deeply. Qualitative research is an approach to explore and understand the meaning- the individuals and group give to a social or human problem. (Creswell, 2013). All interviews were audibly recorded with the permission of the students being interviewed. All of the interview transcripts were read and organized by the researcher into themes and codes. The data was organized then into themes, sub-themes and further into coding whenever deemed necessary. Thematic analysis is a method of identifying, analyzing and interpreting themes in qualitative research data(Manning, 2014). The aim of the thematic analysis is to obtain a condensed and broad description of the phenomenon Braun, 2014). The major themes were first identified after going through the review of existing literature on the subject. After that through cutting and sorting techniques, sub-themes were identified. Cutting and sorting is a more formal way of pawing (Piercy, 2015). The researcher first went through the text and identified quotes that seemed somehow important. Each quote was cut out making sure to maintain the context with the reference name and then organize them into piles of similar quotes. After that, each pile was named in accordance with repetition of concepts. The findings from each pile were drawn in order to give meaning to the data. The quotes are mentioned by the designation of the respondents to maintain their confidentiality.

As far as the validity of the data is concerned, two independent researchers from University Tun Hussein Onn Malaysia were asked to verify and validate the accuracy of the categorization of themes and subthemes. After discussion with them, minor modifications were made to the analysis and coding. The data was also validated by pictures and videos of the respondents being an an interview. The analyzed data was validated through sending it in written form it to all the respondents for verification.

\section{Results and discussion}

The responses of the employees to each of the questions are analyzed. The principal author is familiar with the actual experiences by the employees interviewed due to having sufficient working experience in a number of developing organizations in Pakistan. This firsthand knowledge by the author helped this study tremendously. In order to avoid the personal bias of the author in the analysis, "bracketing" was ensured. Bracketing refers to "self-awareness of mindset" of the researcher (Hutchinson, 1986). Besides, the principal author wrote a personal statement of experiences and perceptions which she expected to have about the causes, outcomes and resolution of communication conflicts in order to become conscious of the perceptions and beliefs of employees even before collecting data and during the process of research, (see Appendix 2 for the personal statement)

\section{Profile of respondents}

The respondents for this study belonged to three organizations presented in the following Table 1

Table 1: Gender * Organization Cross tabulation

\begin{tabular}{|c|c|c|c|c|c|}
\hline & & CMDO & ICMC & Read Foundation & Total \\
\hline \multirow[t]{2}{*}{ Gender } & Female & 0 & 5 & 0 & 5 \\
\hline & Male & 5 & 2 & 6 & 13 \\
\hline Total & & 5 & 7 & 6 & 18 \\
\hline
\end{tabular}

The gender imbalance was quite expected as the two organizations did have female staff. The average age of the respondents was calculated as 32 years while the average length of working experience is 8 years of the total 18 respondents. Besides, the designation of the respondent was as the following Tabe 2

\begin{tabular}{l} 
Table 2: Designation of employees \\
\hline Child Protection Officer \\
Donor relation Officer \\
Program Manager \\
Project Coordinator \\
Program Director \\
Finance Assistant \\
Finance Manager \\
HOD International relations \\
HOD M\&E \\
HR Officer \\
Interpreter \\
Interpreter \\
Assistant reporting officer \\
IT Manager \\
Livelihood Officer \\
M\&E officer \\
Manager M\&E \\
Medical counselor
\end{tabular}

\section{Results}

The respondents expressed their point of views regarding the main causes and factors which help trigger communication conflicts among employees at the workplace. The respondents also talked about the ways on how to reduce and tackle these conflicts effectively. According to the findings, there are multiple causes of conflicts. The respondents expressed their feelings in the following words.

\section{Common causes}

I think misunderstanding and miscommunication among employees are the main causes of communication conflict. Lack of 
communication skills in employees is also one of the causes. Besides, written communication should also be effective to reduce conflicts.

\section{(Program Director)}

Another respondent expressed it in the following words

Informal communication and miscommunication usually give birth to conflicts at the workplace. Besides, opposing or different views also causes conflict among employees. One of the potential causes of conflicts is that employees don't understand the conflicting situation that is why they are unable to deal with it effectively".

\section{(Child Protection Officer)}

Another respondent had the following feeling and experience regarding the causes of communication conflicts.

Like others, I also experienced a lot of conflicts. I feel that main cause of any conflict includes poor communication, misunderstanding and lack of mutual interest of employees. Lack of resources or limited resources and unhealthy competition among employees and differences in the personalities of employees causes conflicts as well at the workplace." (Livelihood officer)

\section{Rare causes}

The rare causes were themed as the respondents did not repeat them. Some of the respondents expressed that conflicts occur due to lack of essential soft skills in employees.

Lack of soft skills and traits such as anger management, patience, and tolerance mostly triggers communication conflicts. I think patience and tolerance are the most required skills in the today's workplace. While for the effective resolution of these conflicts, organizations should train their staff on sharpening these skills regularly.

\section{(HR Officer)}

One of the rare causes of conflicts also include

"Unrealistic expectations and ambiguity in role create and increase communications conflicts."

(IT Manager)

One of the respondents also pinpoints the lack of training as the cause of conflict such as

"Lack of training opportunities for employees also causes conflicts as training sharpens various skills of employees."

\section{(Assistant reporting officer)}

From the above quotes, it can safely be concluded that poor or miscommunication (written or spoken), misunderstanding, unhealthy competition, and limited resources are the most common causes of conflicts among employees at the workplace while the lack of soft skills, lack of training opportunities and unrealistic expectations come under rare causes of conflicts.

\section{Most harmful outcomes}

The respondents also expressed their opinions over the damage and harm which the conflicts bring to the employees and organization. After the conflict, sometimes there are resignations and it's hard to find the right caliber of employees. The mutual respect among employees and supervisor is affected. Stress and tension in employees make the things worse.

\section{(Monitoring \& Evaluation Officer)}

Another respondent put it in another way like this

In extreme cases of conflict, there is firing, transferring and resignation but usually at a smaller level, conflict brings a lack of trust, dissatisfaction and bad performance on the part of employees. (Interpreter)

\section{Less harmful outcomes}

One of the respondents shared his thinking and experience about the impact of conflict in the following way like Conflict rarely entail into a productive side because employees mostly don't understand the phenomenon of conflict. Mostly it brings dissatisfaction, lack of trust and respect, and rebellions etc.

(Assistant reporting officer)

Another respondent had almost the same feelings

Conflict usually result into jealousy, dissatisfaction, lack of mutual respect, lack of trust which unstable the position of employees.

(Project Coordinator)

The work is the ultimate sufferer in the conflicting situation.
The greater impact of conflict is that work suffers the most. The quality of work is affected. There is an unhealthy professional environment which provides less opportunity for professional growth and development. (Program Manager)

The impact of conflict can be summarized as the less damaging comes and more damaging outcomes. Lack of trust and respect, dissatisfaction, jealousy, stress and bad performance come under the less damaging aspect of conflict outcomes while resignation and firing and constant absenteeism belong to the most damaging effects of conflicts.

Irrespective of the conflicting nature, there should be initiatives in the very first place, to resolve the conflict wisely and peacefully.

\section{Effective resolution of conflicts}

One of the respondents gives a suggestion for the effective resolution of the conflict in the following words.

The occurrence and effective resolution among employees usually depend on the good management and leadership. In good a leadership, there do arise conflicts but they are resolved constructively. (Project Coordinator)

Likewise, one more respondent expressed his feeling regarding effectively resolving conflicts in the following words

Conflicts can be resolved effectively through regular training of employees and strong leadership and through promoting healthy competition".

(HOD M\&E)

Through the expression of respondents, it can safely be concluded that communication conflict occurs due to mainly miscommunication, lack of communication, lack of tolerance, patience, and mutual respect etc. among employees at the workplace. They usually occur due to unhealthy competition, limited or lack of resources, shared interest, and ineffective leadership. They have adverse outcomes on the organization and people at the workplace such as transferring, firing resignation, lack of trust and respect among employees, stress, dissatisfaction, and jealousy etc. They can be reduced and tackled effectively through training of employees to sharpen their soft skills, good leadership and promoting healthy competition at the workplace.

\section{Discussion}

Our study found out the significant causes of communication conflicts among employees such as poor communication/ miscommunication, unhealthy competition, limited resources, lack of skills and traits and lack of training opportunities for sharpening soft skills etc. Our findings also revealed the significant impact of these conflicts on the employees and organization such as termination, firing, transferring, the appointment of incompetent people, stress, of lack of trust, lack of respect, waste of resources etc. While as for as effective resolution of conflicts is concerned, the study suggested that training of employees (developing their skills and traits), good leadership and promoting healthy competition could help reduce, manage and eventually resolve the communication conflict effectively at the workplace. The information and findings from this research could help employees and employers to look into these potential factors which could improve or disapprove the professional environment and learn how effectively workplace conflicts could be resolved in order to avoid its adverse outcomes. The findings of this study could be generalized to other developing organizations due to the fact that the respondents who shared their feeling and perceptions had working experience in multiple developing organizations. The findings of this study are supported by a number of recent studies. One of the studies conducted on the conflicts in ICU revealed communication issue as one of the primary causes of conflict (Fassier \& Azoulay, 2010). It suggested that improved communication (soft skill) and good leadership could help reduce these conflicts as revealed through the finding of this study. Another study conducted in the universities at Karachi ( Pakistan) suggested that training and counseling to employees could reduce stress and improve job satisfaction of employees (Ali, Raheem, Nawaz, \& Imamuddin, 2014) as suggested by this study. One of a study conducted to know the 
causes of conflicts arising between client and contractors in the construction industry. As also identified by this research, unsuccessful communication was ascertained as one of the main causes of these conflicts (Mitkus \& Mitkus, 2014).

It is important to mention that we focused on the overall causes of communication conflicts in developing sector organizations while future researcher could investigate and narrow down subject looking into the each cause, its after effects and subsequent reduction or resolution also in a different working sector.

\section{Conclusion}

This paper uses a qualitative approach design to collect data from the eighteen employees of the three developing organizations of Islamabad, Pakistan. The findings revealed a number of factors that trigger communication conflict among employees at the workplace including miscommunication, misunderstanding, lack of resources, unhealthy competitions, lack of communication skill, lack of patience, lack of tolerance, lack of mutual respect etc. The major finding of the study concludes that lack of soft skills plays a pivotal role in perpetuating communication conflicts. The finding also reveals the adverse effects of conflict on the employees, organization, and its environment. It was suggested that regular training of employees and promoting of leadership and healthy competition could help reduce conflicts among employees at the workplace. The outcomes of this study are supported by a number of studies conducted recently on the subject.

\section{Ethical consideration}

The researcher took official permission from the head of three developing organizations from which the researcher drew a sample for this study. The employees were debriefed on the description of the study at the beginning of the study so that they could be in better position to respond to their perception. As an ethical requirement, all the records and participants identities were treated as confidential.

\section{References}

Ali, W. U., Raheem, A. R., Nawaz, A., \& Imamuddin, K. (2014). Impact of stress on job performance: An empirical study of the employees of Private Sector Universities of Karachi, Pakistan. Research Journal of Management Sciences ISSN, 2319, 1171.

Ameen, K. (2013). The need and impact of learning "Personality Development \& Communication Skills" in LIS education: a case study. Malaysian Journal of Library \& Information Science, 18(1), 15-25.

Ayoko, O. B., V. J. Callan, et al. (2003. (2003). Workplace conflict, bullying, and counterproductive behaviors. The International Journal of Organizational Analysis, 11(4), 283-301.

Brockman, J. L. (2013). Interpersonal Conflict in construction: Cost, cause, and consequence. Journal of construction engineering and management, $140(2), 04013050$.

Cassum, L. A. (2014). Verbal violence at work place: A reality from Pakistani context. Journal of Nursing Education and Practice, 4(8), p20.

Chaudhry, A. A., M. Sajjad, et al. (2011). (2011). Employees' conflict management strategies and demography: A case of Pakistan. African journal of business management, 5(9), 3549-3555.

Cohen, D., \& Crabtree, B. (2006). Qualitative research guidelines project.

Creswell, J. W. (2013). Research design: Qualitative, quantitative, and mixed methods approaches: Sage publications.

De Dreu, C. K. (2008). The virtue and vice of workplace conflict: Food for (pessimistic) thought. Journal of organizational Behavior, 29(1), 5-18.

Farooqi, M. T. K., M. M. S. Akhtar, et al. (2013). (2013). Conflict Management Styles implemented by the administrators in the public sector universities of Punjab, Pakistan. Scottish Journal of Arts, Social Sciences and Scientific Studies, 10(2), 28-41.

Fassier, T., \& Azoulay, E. (2010). Conflicts and communication gaps in the intensive care unit. Current opinion in critical care, 16(6), 654-665.

Ferreira, M. M. a. A. R. T. (2012). The impact of problem-based learning (PBL) on student attitudes toward science, problem-solving skills, and sense of community in the classroom. The Journal of Classroom Interaction, 47(1), 23.

Longhurst, R. (2003). Semi-structured interviews and focus groups. Key methods in geography, 117-132.
Manning, M. (2014). A Study of Personnel Conflict between Native English Teachers and Korean Management. 한국교양교육학회 학술대회 자료집, 671-688.

Mansoor, M., Fida, S., Nasir, S., \& Ahmad, Z. (2011). The impact of job stress on employee job satisfaction a study on telecommunication sector of Pakistan. Journal of Business Studies Quarterly, 2(3), 50.

Mirza, F. M., A. A. Jaffri, et al. (2014). (2014). An assessment of industrial employment skill gaps among university graduates: In the Gujrat-SialkotGujranwala industrial cluster, Pakistan (Vol. 17): Intl Food Policy Res Inst.

Mitkus, S., \& Mitkus, T. (2014). Causes of conflicts in a construction industry: A communicational approach. Procedia-Social and Behavioral Sciences, $110,777-786$.

Nasir, M., \& Bashir, A. (2012). Examining workplace deviance in public sector organizations of Pakistan. International Journal of Social Economics, 39(4), 240-253.

Nickson, D., Warhurst, C., Commander, J., Hurrell, S. A., \& Cullen, A. M. (2012). Soft skills and employability: Evidence from UK retail. Economic and Industrial Democracy, 33(1), 65-84.

Noor, S., \& Maad, N. (2009). Examining the relationship between work life conflict, stress and turnover intentions among marketing executives in Pakistan. International Journal of Business and Management, 3(11), 93.

Pandey, N., Pandey, A., \& Kothari, D. A. K. (2016). Soft Skills in Defense Services--Need of the Hour. Macro and Micro dynamics for Empowering Trade, industry and Society, 161.

Piercy, K. (2015). Analysis of semi-structured interview data.

Sultana, M. a. S. Z. (2015). Proposing Project Based Learning as an alternative to traditional ELT pedagogy at public colleges in Pakistan. International Journal for Lesson and Learning Studies, 4(2), 155-173.

Yildiz, D. G., \& Bumen, N. T. (2013). Effects of Cooperative Learning and Conflict Resolution Training Integrated into Curriculum on Academic Achievement, Social Problem Solving Skill. Turkish Journal of Education, 2(4).

\section{Appendix 1}

\section{Interview}

\begin{tabular}{l}
\hline Name \\
Age \\
Gender \\
Time \\
Designation \\
\hline
\end{tabular}

Being a doctoral student at UTHM Malaysia, I welcome you to take part in a research study on the "Use of Problem-Based Learning Approach for Employees Training" in Pakistan. The research is part of my doctoral thesis at the Faculty of Science Technology and Human Development in University Tun Hussein Onn of Malaysia. Taking part in research is open to everyone and your response will be recorded with complete confidentiality. You can also withdraw from the survey at any stage of answering with no objection on my side. When responding to questions, you should keep in mind that your feelings and expression is going to contribute to the development of new research findings. Participation in research will not take more than maximum 15 minutes; your cooperation is therefore requested. Please note that this research study is approved by the faculty of Science, Technology and Human Development, UTHM Malaysia and I would like to thank you for your time and support in this regard.

Q 1) Which factors triggers communication conflicts among employees at the workplace in Pakistan? Kindly give a detailed response.

Q 2) Can you kindly state the main causes of communication conflicts among employees at the workplace in Pakistan?

Q 3) How these conflicts can be reduced and resolved effectively?

\section{Appendix 2}

\section{Personal Statement}

Having around seven years of experience five 5 different developing organizations, the author expects the following potential of causes, impact and resolution of communication conflict at the workplace in Pakistan.

- Communication conflicts are usually triggered due to lacking of essential soft skills and traits among employees at the workplace.

- Communication conflicts also occur due to weak or corrupt leadership

- Communication conflict occurs due to lack of resources and unhealthy competitions

- Communication conflict brings dissatisfaction, lack of trust, absenteeism, waste of resources and

- Communication conflict brings resignation, transferring, employing incompetent staff and firing in the extreme cases. 
- According to the belief of researcher, communication conflicts could effectively be resolved through adopting PBL training approach in which

- They can be reduced and resolved through strong leadership and people are grouped together to work on the given problems. 